\title{
Introducing inulin-type fructans
}

\author{
Marcel B. Roberfroid \\ Université Catholique de Louvain, 7A rue du Rondia, B-1348, Louvain-La-Neuve, Belgium
}

Inulin is a generic term to cover all $\beta(2 \rightarrow 1)$ linear fructans. Chicory inulin is a linear $\beta(2 \rightarrow 1)$ fructan (degree of polymerisation (DP) 2 to $60 ; \mathrm{DP} \mathrm{av}_{\mathrm{v}}=12$ ), its partial enzymatic hydrolysis product is oligofructose (DP 2 to $8 ; \mathrm{DP}_{\mathrm{av}}=4$ ), and by applying specific separation technologies a long-chain inulin known as inulin HP (DP 10 to 60; $\mathrm{DP}_{\mathrm{av}}=25$ ) can be produced. Finally, a specific product known as oligofructose-enriched inulin is obtained by combining chicory long-chain inulin and oligofructose. Because of the $\beta$-configuration of the anomeric $\mathrm{C}_{2}$ in their fructose monomers, inulin-type fructans resist hydrolysis by intestinal digestive enzymes, they classify as 'non-digestible' carbohydrates, and they are dietary fibres. By increasing faecal biomass and water content of the stools, they improve bowel habits, but they have characteristic features different from other fibres. They affect gastrointestinal functions not because of their physico-chemical properties but rather because of their biochemical and physiological attributes. In the colon, they are rapidly fermented to produce SCFA that are good candidates to explain some of the systemic effects of inulin-type fructans. Fermentation of inulin-type fructans in the large bowel is a selective process; bifidobacteria (and possibly a few other genera) are preferentially stimulated to grow, thus causing significant changes in the composition of the gut microflora by increasing the number of potentially health-promoting bacteria and reducing the number of potentially harmful species. Both oligofructose and inulin are prebiotic. They also induce changes in colonic epithelium stimulating proliferation in the crypts, increasing the concentration of polyamines, changing the profile of mucins, and modulating endocrine as well as immune functions. From a nutrition labelling perspective, inulin-type fructans are not only prebiotic dietary fibres; they are also low-calorie carbohydrates $[6.3 \mathrm{~kJ} / \mathrm{g}(1.5 \mathrm{kcal} / \mathrm{g})]$. Supported by the results of a large number of animal studies and human nutrition intervention trials, the claim 'inulin-type fructans enhance calcium and magnesium absorption' is scientifically substantiated, but different inulin-type fructans have probably a different efficacy (in terms of effective daily dose), the most active product being the oligofructose-enriched inulin. A series of animal studies demonstrate that inulin-type fructans affect the metabolism of lipids primarily by decreasing triglyceridaemia because of a reduction in the number of plasma VLDL particles. The human data largely confirm the animal experiments. They demonstrate mainly a reduction in triglyceridaemia and only a relatively slight decrease in cholesterolaemia mostly in (slightly) hypertriglyceridaemic conditions. Inulin appears thus eligible for an enhanced function claim related to normalization of blood triacylglycerols. A large number of animal data convincingly show that inulin-type fructans reduce the risk of colon carcinogenesis and nutrition intervention trials are now performed to test that hypothesis in human subjects known to be at risk for polyps and cancer development in the large bowel.

This paper served as an introduction to the 4th International ORAFTI Research Conference on Inulin and Oligofructose that was held in Paris, La Cité des Sciences, in February 2004. To set the scene, it refers to the concept of 'functional food'. To clearly define the products that were evaluated during the conference, it gives a full description of the chemistry and the nomenclature of the inulin-type fructans. To give an overview of the physiological properties of these food ingredients, it summarizes the data available at the time of the meeting; but for full details it refers to the proceedings of the second and the third conferences (references ORC 2 and ORC 3), to the specialized papers published in this supplement, as well as to the book entitled Inulintype Fructans as Functional Food Ingredients (Roberfroid, 2004, 2005).

\section{Concept of functional food}

As the science of nutrition progresses, a wide variety of foods are or will in the future be characterized as functional food, with a variety of components affecting a variety of body functions relevant to either a state of well-being and health and/or to the reduction of the risk of a disease.
To elaborate the concept of 'functional food', the European Commission's Concerted Action, known as Functional Food Science in Europe (FUFOSE), has considered the following features:

- conventional/everyday food or food ingredient;

- naturally occurring in foods;

- proven beneficial effect(s) on target functions beyond nutritive value/basic nutrition;

- proofs of enhanced well-being and health and/or reduced risk of a disease and/or improved quality of life including physical, psychological and behavioural performances.

A consensus known as the European Consensus on 'Scientific Concepts of Functional Foods' (Diplock et al. 1999) proposes the following working definition of a functional food:

'A food can be regarded as functional if it is satisfactory demonstrated to affect beneficially one or more target functions in the body, beyond adequate nutritional effects, in a way that is relevant to either improved stage of health and well-being and/or reduction of risk of disease. A functional food must remain food and it must demonstrate its effects in amounts that can normally be expected to be 
consumed in the diet: it is not a pill or a capsule, but part of the normal food pattern.'

As described in that consensus (Diplock et al. 1999):

'The design and development of functional foods is a key issue, as well as a scientific challenge, which should rely on basic scientific knowledge relevant to target functions and their possible modulation by food components.'

Emphasis is then put on the importance of 'the effects of food components on well-identified and well-characterized target functions in the body that are relevant to well-being and health issue, rather than, solely, on reduction of disease risk'.

In order to achieve such a development, it is necessary to:

- Identify potential functional foods or functional food components and, at least partly, understand the mechanism(s) by which they modulate target function(s) that are recognized or proven to be relevant to the state of well-being and health, and/or the reduction of a disease risk.

- When such a functional effect is demonstrated, it will be used to formulate hypotheses to be tested in human nutrition intervention studies. The aim of such studies will be to test the effect of a food or a food ingredient as part of the ordinary diet to be consumed, in most cases, by the general population or, generally large target groups at risk. But they should not use a risk $v$. benefit approach. Most of these studies will rely on change(s) in validated/relevant markers to demonstrate a positive modulation of target functions after (longterm) consumption of the potential functional food or food ingredient.

- Such a modulation will then be translated into claims that should be based on effects which go beyond what could be expected from the established role of diet. If such effects concern a target function or a biological activity without direct reference to a particular disease or pathological process, claim will be made for an 'enhanced function'. But, if the benefit is clearly a reduction of the risk of a disease or pathological process, claim will be made for a 'disease risk reduction'. These two types of claims, that are specific for functional foods, are identified in the European consensus document as the 'type A' and 'type B' claims, respectively (Diplock et al. 1999).

Amongst the main targets for functional food development, the physiology of the large bowel and the composition and activities of the microbial ecosystem which colonizes it are major targets that are attracting a great deal of interest, as shown by the most recent developments in the fields of probiotic, prebiotic and synbiotic (Gibson \& Roberfroid, 1999; Hanson \& Yolken, 1999; Roberfroid et al. 2002). Amongst these, inulin-type fructans are unique owing to their chemical nature and the combination of their effects that affect gastrointestinal functions not because of their physico-chemical properties, but rather because of their biochemical and physiological attributes.

\section{Inulin-type fructans: chemistry and nomenclature}

Inulin-type fructans are present in significant amounts in several fruits and vegetables (Van Loo et al. 1995). The average daily consumption has been estimated to be between 3 and $11 \mathrm{~g}$ in Europe (Van Loo et al. 1995) and between 1 and $4 \mathrm{~g}$ in the USA (Moshfegh et al. 1999), the most common sources being wheat, onion, banana, garlic and leek.

Chemically, inulin-type fructans are a linear polydisperse carbohydrate material consisting mainly, if not exclusively, of $\beta-(2 \rightarrow 1)$ fructosyl-fructose linkages (Waterhouse \& Chatterton, 1993). A starting $\alpha$-D-glucose moiety can be present but is not necessary. $\mathrm{G}_{\mathrm{py}} \mathrm{F}_{n}$ (glucopyranosyl-(fructofuranosyl) ( $_{n-1}$-fructose) and $\mathrm{F}_{\mathrm{py}} \mathrm{F}_{n}$ (fructopyranosyl-(fructofuranosyl) ${ }_{n-1}$-fructose) compounds are included under that same nomenclature and they are both a mixture of oligomers and polymers that are best characterized by the average $\left(\mathrm{DP}_{\mathrm{av}}\right)$ and the maximum $\left(\mathrm{DP}_{\mathrm{max}}\right)$ degree of polymerization or DP.

The only plant that has so far been used industrially for the extraction of inulin-type fructans belongs to the Compositae family, i.e. chicory. Native chicory inulin is a non-fractionated inulin extracted from fresh roots that always contain glucose, fructose, sucrose and small oligosaccharides (De Leenheer, 1996). Because of the $\beta$-configuration of the anomeric $C_{2}$ in its fructose monomers, inulin-type fructans resist hydrolysis by human small intestinal digestive enzymes, which are specific for $\alpha$-glycosidic bonds. They have thus been classified as 'non-digestible' oligosaccharides (Delzenne \& Roberfroid, 1994; Roberfroid \& Slavin, 2000).

The DP of chicory inulin varies from 2 to more or less 60 units with $\mathrm{DP}_{\mathrm{av}}=12$. About $10 \%$ of the fructan chains in native chicory inulin have a DP ranging between $2\left(\mathrm{~F}_{2}\right)$ and $5\left(\mathrm{GF}_{4}\right)$. The partial enzymatic hydrolysis of inulin using an endo-inulinase (EC 3.2.1.7) produces oligofructose that is a mixture of both $\mathrm{G}_{\mathrm{py}} \mathrm{F}_{n}$ and $\mathrm{F}_{\mathrm{py}} \mathrm{F}_{n}$ molecules, in which the DP varies from 2 to 7 with $\mathrm{DP}_{\mathrm{av}}=4$. It is composed primarily of lower DP oligosaccharides, namely 1-kestotriose, 1,1-kestotetraose and 1,1,1-kestopentaose, as well as inulobiose, inulotriose and inulotetraose. Oligofructose can otherwise be obtained by enzymatic synthesis (transfructosylation) using the fungal enzyme $\beta$-fructosidase (EC 3.2.1.7) from Aspergillus niger. In that reaction, in a process similar to the plant biosynthetic pathway, sucrose serves as a substrate to which 1,2 or 3 additional fructose units are added by forming new $\beta-(2 \rightarrow 1)$ linkages. In such a synthetic compound, DP varies from 2 to 4 with $\mathrm{DP}_{\mathrm{av}}=3.6$ and all oligomers are of $\mathrm{G}_{\mathrm{py}} \mathrm{F}_{n}$ type. In the oligofructose-enriched inulin or Synergy ${ }^{\circledR} 1$ type products, two distinct populations of low- and high-molecular-weight compounds are mixed, thus creating a unique type of oligosaccharides. The general molecular structure of inulin-type fructans is shown in Fig. 1.

In the papers of these proceedings the term inulin-type fructan shall be applied as a generic term to cover all $\beta-(2 \rightarrow 1)$ linear fructans when the properties reviewed concern all types of molecules. In any other circumstances that justify the identification of the oligomers $v$. the polymers, the terms oligofructose and/or inulin will be used, respectively. Even though the inulin hydrolysate and the synthetic compound have a slightly different $\mathrm{DP}_{\mathrm{av}}$ (4 and 3.6, respectively), the term oligofructose shall be used to identify both. Indeed, oligofructose and (short-chain) fructooligosaccharides are considered to be synonyms to name the mixture of small inulin oligomers with $\mathrm{DP}_{\max }<10$ (Quemener et al. 1994; Roberfroid \& Delzenne, 1998; Coussement, 1999; Perrin et al. 2001; Roberfroid, 2002). Moreover, as outlined by Farnworth (1993), 'although the initial findings (on the effects of inulin) were based on Neosugar (the synthetic or so-called short-chain fructooligosaccharide), it has become evident that many of the conclusions extend to other sources of dietary fructans (and especially inulin and inulin derivatives)'. The term inulin will 


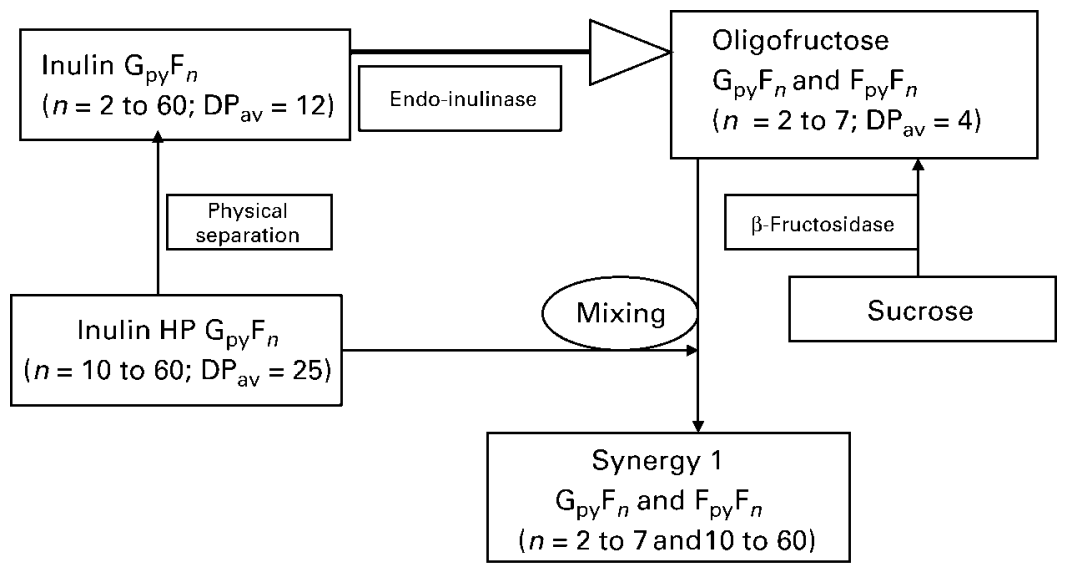

$$
\begin{aligned}
& \mathrm{G}_{\mathrm{py}} \mathrm{F}_{n}=\alpha \text {-D-glucopyranosyl-[ }[\beta-\mathrm{D} \text {-fructofuranosyl }]_{n-1}-\beta \text {-D-fructofuranoside } \\
& \mathrm{F}_{\mathrm{py}} \mathrm{F}_{n}=\alpha \text {-D-fructopyranosyl-[ }[\beta \text {-D-fructofuranosyl }]_{n-1}-\beta \text {-D-fructofuranoside }
\end{aligned}
$$

Fig. 1. Chemical description of chicory inulin and oligofructose and derivatives. DP, degree of polymerisation.

be used to identify both native chicory inulin and any other derived industrial products except oligofructose. The long-chain inulin or inulin HP is produced by applying physical separation techniques to eliminate all oligomers with a DP $<10$. The product known as Synergy ${ }^{\circledR} 1$ is obtained by mixing oligofructose and inulin HP.

\section{Inulin-type fructans as dietary fibre}

Because of the $\beta-(2 \rightarrow 1)$ configuration of the fructosyl-fructose osidic linkages, inulin-type fructans are plant carbohydrates that resist digestion in the upper gastrointestinal tract but are fermented in the colon. By increasing faecal biomass and water content of the stools, they improve bowel habits. For all these reasons, they are undoubtedly part of the dietary fibre complex (Roberfroid, 1993). Indeed, the five basic attributes of a dietary fibre are

- components of edible plant cell;

- carbohydrates (both oligosaccharides and polysaccharides);

- resistance to hydrolysis by human (mammal) alimentary enzymes;

- resistance to absorption in the small intestine;

- hydrolysis and fermentation (partial or total) by the bacteria in the large bowel.

And inulin-type fructans

- are part of edible plants;

- are carbohydrates that are composed of a mixture of either oligosaccharides or oligosaccharides and polysaccharides;

- resist hydrolysis by human digestive enzymes;

- do not appear to be significantly absorbed in the small intestine, except possibly for the very-short-chain oligosaccharides (di- and trisaccharides; Menzies, 1974);

- are hydrolysed and completely fermented by the colonic microflora and are oxidized to produce gases and SCFA.

They classify as "carbohydrates (oligo- and polysaccharides) that resist both hydrolysis by mammal digestive enzymes and absorption in the small intestine but are, at least partly, hydrolysed and fermented by the colonic microflora'.
They must be labelled as dietary fibre on consumer food products. But, and because of their specific fermentative properties, they do have characteristic features different from those of other fibres. Therefore, they may contribute in a significant way to a well-balanced diet by increasing the fibre content, by improving the diversity of the fibre sources and by their specific effects on several gastrointestinal functions (composition of intestinal microflora, mucosal functions, endocrine activities, mineral absorption, etc.) and even on systemic functions (especially lipid homeostasis and immune functions).

\section{Inulin-type fructans: effects on physiological functions}

Amongst the physiological functions that will benefit most from inulin-type fructans, the gastrointestinal functions are certainly primary endpoints. Amongst others, one of the most promising effects is modulation of the activity of the colon which is more and more recognized to play an essential role in maintaining health and well-being as well as reducing the risk of diseases (Gibson \& Roberfroid, 1995; Cummings, 1997).

Disturbances of the colon's functions may lead to dysfunction not only in the gut but also in the whole body. The classical view that the human colon is an organ that absorbs salt and water and provides a mechanism for the orderly disposal of digestion waste products is no longer appropriate. Indeed, the colon has a major role in digestion (as achieved by the microbial fermentation) through the salvage of energy, and possibly nitrogen, from carbohydrate and protein not digested in the upper gut. But it also plays important roles in (Rowland, 1988; Berg, 1996; Cummings, 1997; Cummings \& Macfarlane, 1997)

- the absorption of minerals and vitamins;

- the production and absorption of fermentation endproducts like SCFA and lactate;

- the protection of the body against translocation of bacteria;

- the protection of the body against the in situ proliferation of pathogens;

- the endocrine functions (via the gastrointestinal peptides); 
- the regulation of intestinal epithelial cell growth and proliferation;

- the immune function.

The concept of 'colonic health' has thus emerged and is becoming a major target for functional food development in the area of enhanced function claims (Salminen et al. 1998). Besides its important physiological and immunological functions, the colon is also involved in miscellaneous diseases from acute infections and diarrhoea or constipation to chronic diseases like inflammatory bowel diseases, irritable bowel syndrome and cancer (Cummings, 1997).

Through modulation of the colonic functions, inulin-type fructans have thus also the potentiality to reduce the risk of some diseases.

\section{Concept of balanced colonic microflora}

The microflora that symbiotically colonizes the large bowel is a key player in maintaining the colon (and thus the whole body) healthy. A major determinant in that role is the composition of the microflora, which

- is largely determined by the flora that establishes at and immediately after birth;

- can be modulated by specific compounds in the diet;

- may change during life, becoming more and more complex as we age (Blaut et al. 2002).

To support health and well-being and to reduce the risk of various diseases, it has been hypothesized that the gut microflora must remain a 'balanced microflora'. That concept implies that the gut (especially colon) microflora must be composed predominantly (in numbers) of bacteria recognized as potentially healthpromoting (like lactobacilli, bifidobacteria, fusobacteria) to prevent, impair or control the proliferation of the potentially pathogenic/harmful micro-organisms (like some Escherichia coli, clostridia, veillonellae, candida; Gibson \& Roberfroid, 1995). But that does not mean that the micro-organisms in this last category are useless and must necessarily be eliminated. Indeed the colonic microflora is a complex 'ecosystem' with a wide variety of potential interactions between the different populations of micro-organisms. Thus, it cannot be excluded that some interactions between potentially health-promoting and (low number of) potentially harmful bacteria and/or micro-organisms do in fact play a role in maintaining health and well-being and in reducing the risk of some diseases. It is thus possible that some populations of potentially harmful or even pathogenic bacteria are necessary provided they remain small in number compared to the health-promoting species. This is particularly true for the species that are recognized as being both potentially health-promoting and potentially harmful. We are still in a phase of exploration of the colonic microflora in terms of its composition at species but also strain levels but we still largely ignore most of the activities of these micro-organisms and even more so the interactions, exchanges and complementarities that exist between the different genera, species and strains.

The hypothesis has thus been formulated that, through modulation of the composition of the colonic microbiota (i.e. by stimulating the growth of potentially health-promoting bacteria and suppressing, or at least reducing the number, of potentially harmful micro-organisms), dietary strategies might be developed to improve colonic health and thus, indirectly, the health and wellbeing of the host as well as the ability to reduce the risk of various diseases. Indeed (Roberfroid, 1998) such a strategy is at the origin of the concept of prebiotics aimed towards stimulation of the growth of potentially beneficial bacteria, the ultimate aim of supplementation of the human diet with prebiotics being the beneficial management of the gut microbiota.

\section{Concept of prebiotic}

A prebiotic is a selectively fermented ingredient that allows specific changes, both in the composition and/or activity in the gastrointestinal microflora that confers benefits upon host well-being and health. (Gibson et al. 2004)

The classification of a food or a food ingredient as prebiotic requires a scientific demonstration that it

- resists gastric acidity, hydrolysis by mammalian enzymes and gastrointestinal absorption;

- is fermented by intestinal microflora; and

- selectively stimulates the growth and/or activity of intestinal bacteria associated with health and well-being (Gibson \& Roberfroid, 1995).

Thus, prebiotic fermentation should be directed towards bacteria seen as health-promoting, with indigenous lactobacilli and bifidobacteria currently being the preferred targets, and with special attention to the bifidobacteria that are considered as the main health-promoting group in gut microflora (Gibson, 1998). Indeed, Bifidobacterium spp. dominate the gut microflora of breast-fed infants and they are thought to play an important role in the improved health and development of breast-fed infants as compared to those who are formula-fed.

\section{Inulin-type fructans are prebiotics}

Inulin and oligofructose are the most studied and well-established prebiotics. As previously mentioned they escape digestion in the upper gastrointestinal tract and reach the large intestine virtually intact, they are quantitatively fermented and act as prebiotics. Indeed, in the many studies that investigated the effects of inulin and oligofructose on the human gut microbiota both in vitro and in vivo, a selective stimulation of growth of the beneficial flora, namely bifidobacteria, to lesser extent lactobacilli and possibly other species like Clostridium coccoides-Eubacterium rectale cluster known to be a butyrate producer has been reported (Kleessen et al. 2001; Apajalahti et al. 2002). The mechanism of the bifidogenic effect of inulin and oligofructose is thought to be their selective fermentation by the bifidobacteria that produce an intracellular inulinase necessary to hydrolyse the $\beta-(2 \rightarrow 1)$ fructosyl-fructose osidic linkages. But these data also call attention to the facts that not all inulin derivatives have, qualitatively, the same effects on intestinal microflora and that, for each inulin-type fructan, the different segments of the large bowel (including the faeces) might be differently influenced.

Human trials with oligofructose and inulin include those with a controlled diet, a free diet and cross-over feeding trials although the dose, substrate, duration, volunteers as well as bacteriology vary (Sano, 1986; Takahashi, 1986; Mitsuoka et al. 1987; Hidaka et al. 1991; Williams et al. 1994; Gibson et al. 1995; Buddington et al. 1996; Kleessen et al. 1997; Bouhnik et al. 
1999; Menne et al. 2000; Rao, 2001; Tuohy et al. 2001a,b; Guigoz et al. 2002; Harmsen et al. 2002). In these in vivo trials, there were large variations between the subjects in their microflora compositions (analysed by applying both classical culture and molecular techniques) and responses to the substrates, particularly between Western and Eastern (both European and North American) subjects. Another general observation was the decrease in bifidobacteria once administration of the oligofructose and inulin ceased (Gibson et al. 1995; Bouhnik et al. 1996; Buddington et al. 1996; Kruse et al. 1999; Rao, 2001; Tuohy et al. 2001a,b; Guigoz et al. 2002; Harmsen et al. 2002). In all the nutrition trials so far reported that have tested for the effect of inulin-type fructans on human faecal flora, the increase in the number of bifidobacteria (as expressed as $\mathrm{cfu} / \mathrm{g}$ of faeces)

- becomes significant and reaches its maximum probably in less than a week;

- remains as long as the intake of the prebiotic continues;

- progressively (within 1-2 weeks) disappears when the intake stops.

Such observations are well in line with the hypothesis that the prebiotic acts as a selective substrate for the fermentation of the bifidobacteria that become stimulated to grow.

At the current time, sampling for microbiological analysis is limited to faeces only. Even if it is generally accepted that stools are surrogate for the colonic content, this certainly limits our understanding of what is happening inside the colon and more specifically inside the different segments that are known to differ in their environmental $(\mathrm{pH}$, mineral and water contents, etc.) conditions and in their physiological functions (Cummings, 1997). Even though the bacterial population is certainly much lower there than in the large bowel, it remains that the small intestine, and especially the distal ileum, is also colonized by bacteria, the proliferation of which can well be supported by prebiotics, and faeces is most probably not a good surrogate to study that population and its modulation by prebiotic. There is thus a need to develop new models and new methodologies to allow sampling in these parts of the gastrointestinal tract.

Another topic of growing interest is the bacterial flora colonizing surfaces in the large intestine especially the mucosa, the mucus layer or eventually the particulate materials in the colonic lumen (Macfarlane et al. 1999). Indeed a few studies using either biopsy or resected samples have demonstrated the presence, in the colonic mucosa, of a microflora with a specific composition, different from the luminal colonic microflora (Poxton et al. 1997). In an ex vivo protocol in which fifteen healthy volunteers selected from the colonoscopy waiting list had been asked to supplement their usual diet with Synergy ${ }^{\circledR} 1(15 \mathrm{~g} / \mathrm{d})$ for 2 weeks, preliminary data have shown an increase in both bifidobacteria and lactobacilli counts in the mucosa $\left(+1\right.$ and $0.5 \log _{10} \mathrm{cfu} / \mathrm{g}$ of mucosa, respectively; Langlands et al. 2004). Using the model of rats harbouring a human faecal flora, Kleessen et al. (2003) have similarly reported that feeding an inulin-supplemented diet significantly increased $(16 \times)$ mucosal bifidobacteria $\left(\right.$ cells $/ \mathrm{mm}^{2}$ mucosal surface) even though the stimulation was not significant in the intestinal lumen (for more details see Kleessen et al. this supplement). It can thus be hypothesized that the prebiotic effect of inulin-type fructans concerns both the luminal and the mucosa-associated microflora. It can further be speculated that the micro-organisms of the mucosal microflora play specific roles in the protection of the mucosal epithelium and that changes in the composition of that intestinal environment may influence the functions of the epithelium, e.g. nutrient absorption, endocrine activities, immunological functions, etc.

Two questions that have attracted (too much) attention (mostly for marketing purpose) concern the quantitative aspects of the prebiotic effect. These questions can be formulated as follows:

- Are the different inulin-type fructans equally effective?

- Can a dose-effect relationship be established?

To answer these questions the data of all the human studies published have been compiled. By calculating the absolute numbers (expressed either as such or as $\log _{10}$ values) of 'new' bacterial cells that have appeared as a consequence of the prebiotic treatment it was shown that the daily dose of the prebiotic does not correlate with these numbers $(r=0.06$ and -0.09 , respectively; NS). The daily dose of the prebiotic is thus not a determinant of the prebiotic effect; even if, in one group of volunteers with relatively similar initial counts of faecal bifidobacteria, a limited dose-effect relationship has been established (Bouhnik et al. 1999). The reason is that an important parameter, i.e. the initial number of bifidobacteria, is not taken into account. In the first report of a prebiotic effect, Hidaka et al. (1986) have already argued that the initial numbers of bifidobacteria (expressed as $\log _{10} \mathrm{cfu} / \mathrm{g}$ of faeces) influence the prebiotic effect after observing an inverse correlation between these numbers and their 'crude' increases after oligofructose feeding. Roberfroid et al. (1998), Rao (2001) and Rycroft et al. (2001) have reached the same conclusion that is also supported by the meta-analysis $(r=-0.76$; $P<0 \cdot 01)$. At the population level it is the faecal flora composition (especially the number of bifidobacteria) characteristic to each individual that determines the efficacy of a prebiotic but not necessarily the dose itself. The ingested prebiotic stimulates the whole indigenous population of bifidobacteria to growth, and the larger that population, the larger the number of new bacterial cells appearing in faeces. The 'dose argument' (often used as a marketing argument) is thus not straightforward and it cannot be generalized because, as supported by the scientific data, the factors controlling the prebiotic effect are multiple. The 'dose argument' can thus be misleading for consumers and should not be allowed.

To further discuss the prebiotic effect of inulin-type fructans, we propose to use the absolute values of 'new' cells to calculate a 'prebiotic index' defined as: 'the increase in bifidobacteria expressed as the absolute number $(N)$ of "new" cfu/g of faeces divided by the daily dose (in $g$ ) of inulin-type fructan ingested in each individual human nutrition trial' (Roberfroid, 2005).

Based on the available data, it has been concluded that the prebiotic index of inulin-type fructans is of the order of a few $10^{8} \mathrm{cfu} / \mathrm{g}$ (i.e. average $=4.00 \pm 0.82$; range $0.3-13$ ) and that it is comparable for the different types of inulin, especially oligofructose and inulin (averages $4 \times 10^{8}$ and $5 \times 10^{8} \mathrm{cfu} / \mathrm{g}$ and ranges $0 \cdot 5-12 \times 10^{8}$ and $0.3-13 \times 10^{8} \mathrm{cfu} / \mathrm{g}$, respectively).

One important question remaining unanswered is the effect of prebiotic, especially inulin-type fructans, not on the numbers of bacteria, especially bifidobacteria, but rather on activities associated with these bacteria. Indeed the health benefits for the host are part of the definition ('confers benefits upon host well-being and health'; Gibson \& Roberfroid, 1995; Gibson et al. 2004) and these benefits are directly dependent on what these bacteria do, how they interact with the others, and how they modulate intestinal 
functions. Miscellaneous bacterial enzyme activities like glucuronidase, glucosidase, nitroreductase; metabolites like SCFA; or endproducts of the fermentation of amino acids, mucins or sterols (especially primary and secondary bile acids) have been measured and shown to vary (increase or decrease) after feeding prebiotics. But the validity of these parameters still remains to be established especially in terms of their value as biomarkers of colonic and eventually host health and wellbeing or disease risk reduction. In that context the effects of inulin-type fructans on these parameters reported so far are contradictory and difficult to interpret (Buddington et al. 1996; Kleessen et al. 1997; Bielecka et al. 2002b).

In the paper introducing the concept of prebiotics, Gibson \& Roberfroid (1995) also suggested that combining a prebiotic with a probiotic in a 'synbiotic' approach could open new perspectives. Indeed, in vitro experiments designed to test the inhibitory effect of probiotics on the growth of human intestinal pathogens (E. coli, Campylobacter jejuni, Salmonella enteritidis), Fooks \& Gibson (2002) showed that, as compared to other carbohydrates (lactulose, lactitol, dextran, starch), inulin-type fructans (alone or combined with xylooligosaccharides) were observed to strongly support the inhibitory activity. In a rat model, Bielecka et al. (2002a) showed that combining a probiotic $\left(10^{9}\right.$ Bifidobacterium spp. per rat) and oligofructose $(5 \% \mathrm{w} / \mathrm{w}$ in diet) did not improve the prebiotic effect. A few other synbiotic protocols have also been used in experimental carcinogenesis in rats, in the human EU-funded SYNCAN project (Van Loo \& Jonkers, 2001) and in the development of animal feed, and these data are discussed in the papers covering these topics (see Van Loo et al. and Verdonk et al. in this supplement).

\section{Inulin-type fructans and gastrointestinal mineral absorption}

Besides the amount of minerals (especially $\mathrm{Ca}$ and $\mathrm{Mg}$ ) in the diet, the absorption of dietary minerals in foods is also a critical factor in determining their bioavailability. Thus, there is a need to identify food components and/or functional food ingredients that may enhance mineral absorption in order to optimize their bioavailability from foods (Whiting \& Wood, 1997; Weaver \& Liebman, 2002). As stated by Weaver \& Liebman (2002):

'Increasing paracellular absorption (of minerals) is promising because it is not limited by becoming saturated...and it occurs throughout the length of the intestine in contrast to active absorption which is dominant in the duodenum. (...) Ideal compounds would be those that could be incorporated into (mineral)-containing food to enhance absorption...but would have only transient effect, so that transfer of undesirable organisms and ions would be minimized.'

A number of food constituents have attracted attention as potential enhancers of mineral absorption like lactose, casein phosphopeptides (Mellander, 1950; Kennefick \& Cashman, 2000), and non-digestible oligosaccharides especially inulin-type fructans (Fairweather-Tait \& Johnson, 1999; Cashman, 2002).

In experimental animals (mostly the rat), a large number of publications demonstrate that inulin-type fructans significantly increase mineral absorption, essentially $\mathrm{Ca}$ and $\mathrm{Mg}$ (see Weaver this supplement). Except for one study that reported that oligofructose was more efficient than inulin in promoting recovery from postgastrectomy anaemia in rats (Wolf et al. 1998), all inulin-type fructans (native inulin, oligofructose, inulin HP or
Synergy ${ }^{\circledR} 1$ ) were equally effective in modulating mineral absorption even though some qualitative differences might exist when comparing the effects of different types of inulin. In a study aimed at comparing oligofructose, inulin HP and Synergy ${ }^{\circledR} 1$, Coudray et al. (2003) have shown that the latter product was more active than oligofructose or inulin HP alone in enhancing $\mathrm{Ca}$ and $\mathrm{Mg}$ absorption.

The effects of oligofructose have been investigated in a wide variety of particular experimental protocols besides the normal healthy rat. Caecectomized rats as well as rats receiving $\mathrm{Ca}$ and $\mathrm{Mg}$ directly by stomach gavage or by caecal intubation have been used to test for the hypothesis that the effect of inulintype fructans might be mediated through large bowel fermentation. Protocols in which rats were fed an Mg-deficient diet were also used, offering the possibility to demonstrate that improving mineral absorption was an effective way to reduce the incidence of symptoms known to be associated with such deficiencies. The conclusions of all these studies are that inulin-type fructans

- significantly increase mineral, especially $\mathrm{Ca}$ and $\mathrm{Mg}$, absorption;

- protect rats from developing symptoms known to be associated with some mineral deficiencies (essentially $\mathrm{Mg}$ );

- help rats to overcome symptoms of osteopenia;

- restore a close to normal $\mathrm{Ca}$ and $\mathrm{Mg}$ balance in adult virgin female ovariectomized rats.

Because of their high fermentation rate in the large bowel due to the presence of an anaerobic microflora, the effects of inulin-type fructans on minerals are likely to take place primarily in the lower part of the gut. But that is probably more so for $\mathrm{Mg}$ than for $\mathrm{Ca}$, the effects on the former being exclusively mediated in the large bowel whereas for the later it might involve both the upper and the lower gut on a 50/50 basis.

For both $\mathrm{Ca}$ and $\mathrm{Mg}$ the relative increase in intestinal absorption has been shown to highly significantly inversely correlate with the basal absorption capacity, being higher when basal absorption is lower. Since Ca absorption capacity decreases with age, the relative increase in absorption induced by inulintype fructans increases as animals become older.

Since it has been shown that the beneficial effects of inulintype fructans on mineral absorption still persist after ovariectomy, it can be hypothesized that, in females, such effects are hormoneindependent.

In young growing rats, two studies have shown that the effects of oligofructose might decrease with the length of the treatment indicating a possible adaptation and/or a possible feedback down-regulation of the active absorption. However, these observations need more specific investigations.

In man, inulin-type fructans have no effect on mineral absorption in the small intestine and their effects on $\mathrm{Ca}$ and $\mathrm{Mg}$ absorption are likely to be mediated via changes in the lower part of the gut that are mediated by the activity of the microflora. The most convincing data have been obtained in adolescents (Yamada, 1994; Van den Heuvel et al. 1998; Griffin et al. 2003) and in postmenopausal women (Tahiri et al. 2003; Holloway et al. 2005), but one study has confirmed these effects in adult men (Coudray et al. 1997). An interesting conclusion of the studies in adolescents is the inverse correlation between the relative increase in absorption caused by inulin-type fructans and the basal absorption capacity as measured before the intervention. The same correlation was demonstrated when analysing the animal data, indicating that, 
with regard to mineral absorption, consuming inulin-type fructans would benefit more those adolescents who have a low level. Since genetic polymorphisms are known to account for differences in $\mathrm{Ca}$ absorption, it has been speculated that some genotypes could be more likely to benefit from consumption of inulin-type fructans and especially Synergy ${ }^{\circledR} 1$ (Griffin et al. 2003).

Two Japanese studies have recently appeared that claim for an acute enhancing effect on $\mathrm{Ca}$ absorption of a food supplement containing both oligofructose $(3 \mathrm{~g})$ and $\mathrm{Ca}(300 \mathrm{mg}$ - as sole source during the trial period) in a 10:1 ratio. These data are difficult to understand and it remains to be demonstrated that the small increase in urinary $\mathrm{Ca}$ excretion was actually coming from the newly absorbed Ca pool (Stürup et al. 1997; Ohta et al. 1999). Uenishi et al. (2002) did attempt to answer that question by adding a tracer dose of ${ }^{44} \mathrm{Ca}$ and measuring the ${ }^{44} \mathrm{Ca}:{ }^{43} \mathrm{Ca}$ ratio in the urine samples. But since that parameter increased significantly only at two time points, i.e. 8 and $10 \mathrm{~h}$ after oligofructose feeding, no firm conclusion can be made. Moreover, using a similar protocol, Teuri et al. (1999) reported no difference in Ca urinary excretion after ingestion of a single dose of inulin.

All these findings show that regular intake of even modest amounts of inulin-type fructans might significantly increase $\mathrm{Ca}$ and $\mathrm{Mg}$ absorption in girls at or near menarche and in postmenopausal women, with adequate or high $\mathrm{Ca}$ intakes, without any compensatory increase in urinary excretion. But investigation of the effects on more sophisticated measures of $\mathrm{Ca}$ metabolism and on bone mineral accretion, bone resorption and bone turnover rates are required. Still, the findings of the above studies strongly suggest that addition of inulin-type fructans to food represents an opportunity for increasing the uptake of $\mathrm{Ca}$ present in the diet even if further studies are necessary to prove that the benefits of these ingredients to $\mathrm{Ca}$ absorption persist in the longer term and, importantly, that they can be translated into benefits to bone health. Experimental data do already support the hypothesis that the beneficial effects of inulin-type fructans target not only the mineral absorption phase but also other aspects of bone health, especially bone mineralization, bone density, bone accretion and resorption, i.e bone turnover. However, to what extent observations on mineral balance allow assumptions on bone mineralization or bone quality requires information on the persistence of the stimulating effect of inulin-type fructans on mineral absorption, and on the relevance of improved $\mathrm{Ca}$ absorption with respect to bone mineralization, bone density and bone structure. (For more detailled discussion of the effects of inulin-type fructans on mineral absorption see Griffin et al., Coxam and Weaver in this supplement.)

\section{Inulin-type fructans and lipid metabolism}

Modulation of either the digestion/absorption or the metabolism of lipids is another physiological effect of inulin-type fructans that affect triglyceridaemia and cholesterolaemia as well as the distribution of lipids between the different lipoproteins in favour of a more beneficial health pattern (Delzenne et al. 2002).

Indeed, a series of animal studies demonstrate that inulin-type fructans affect the metabolism of the lipids primarily by decreasing triglyceridaemia both in the fasted and the postprandial state. In animals fed a diet supplemented with $10 \%$ inulin or oligofructose, triglyceridaemia is reduced by 36 (SEM 3.4 ) \% (mean value of eight different studies). The effect on cholesterolaemia is less constant, being statistically significant in only part of the studies so far reported. These decreases are likely to be due to a reduction in the number of VLDL particles with the same composition in lipids and the same size. Similar effects have also been demonstrated in rats and hamsters fed with hyperlipidaemic diets. In homozygous $\mathrm{LDL}^{-1-}$ mice, inulin significantly reduced cholesterol both in the serum and in the lipoproteins. The human data largely confirm the animal experiments. They demonstrate mainly a reduction in triglyceridaemia and only a relatively slight decrease in cholesterolaemia both in normo- and (slightly) hypertriglyceridaemic conditions. In human nutrition intervention trials, inulin appeared to be more effective than oligofructose in reducing triglyceridaemia whereas in animals (especially in rats) both products were equally active. With respect to the mechanism, adding inulin-type fructans to the rodent diet reduces liver lipogenesis by reducing the expression of the genes coding for the lipogenic enzymes. A similar mechanism is likely to operate in man. Indeed Letexier et al. (2003) have demonstrated a reduced hepatic lipogenesis but not cholesterol synthesis in subjects receiving $10 \mathrm{~g}$ inulin/d. However, and especially in situation of more severe dysbalances in lipid homeostasis, other mechanisms might also operate like an enhanced catabolism of triacylglycerol-rich lipoproteins.

Whatever the mechanism is, the question still remains open of the links between the gastrointestinal site of the fermentation (and thus the disappearance) of inulin-type fructans and their effect on lipid homeostasis inside the body (the so-called systemic effect). Different hypotheses have been tested to tentatively answer that question:

- Modifications of glucose and/or insulin levels but the effects of inulin-type fructans on glycaemia and insulinaemia are not yet fully understood and available data are still conflicting, indicating that they may depend on physiological (fasting $v$. postprandial state) or disease (diabetes) conditions (Brichard, 1997; Kok et al. 1998; Daubioul et al. 2000; Perrin et al. 2003).

- Modifications of the absorption of macronutrients, especially carbohydrates either by delaying gastric emptying and/or shortening small intestinal transit time (Oku et al. 1984). It must be emphasized however that inulin-type fructans do not have the high viscosity of other non-starch polysaccharides, a physical property that is usually correlated with their effect on absorption of macronutrients.

- Increased production of fermentation endproducts, especially propionate that is absorbed via the portal vein (Demigné et al. 1999), where its concentration is increased by more than 2 fold in oligofructose-fed rats (Roberfroid \& Delzenne, 1998) to reach a concentration shown to inhibit the carrier-mediated acetate uptake and to decrease the concentration of fatty acid synthase mRNA in cultured isolated hepatocytes (cited in Delzenne et al. 2002).

- Increased concentration of polyamines, especially putrescine, as has been observed in the caecum of oligofructose-fed rats (Delzenne et al. 2000).

- Changes in the production of gut peptides (see Delzenne et al. in this supplement).

With regard to their effects on triglyceridaemia, inulin-type fructans fulfil the criteria of a type A claim according to the European consensus on 'Scientific Concepts of Functional Foods' (see above). Indeed their dietary consumption significantly reduces the concentration of blood triacylglycerols, a beneficial effect that is well documented in experimental ani- 
mals in which a series of experiments have led to formulate a sound hypothesis regarding the mechanism.

In (slightly) hypertriglyceridaemic human subjects as well as in subjects prone to develop such lipid dysbalances (e.g. because of consumption of high-carbohydrate diets), inulin has been shown in the small number of studies (3/4) to significantly reduce $(-19 \%)$ triglyceridaemia. Moreover a recent publication has given support to the hypothesis that, like in the rat, this effect could originate from a reduced hepatic lipogenic capacity due to inulin feeding (Letexier et al. 2003). At the present time, human data have demonstrated such effects only for inulin and not for oligofructose, but more work is needed to definitively prove such a qualitative difference between these two fructans. In conclusion, inulin appears thus eligible for an enhanced function claim mostly related to normalization of blood triacylglycerols level even though an effect on cholesterolaemia cannot be ruled out. Since hypertriglyceridaemia is recognized as an independent risk factor for CVD and atherosclerosis, the approval of such a claim and its communication to the consumers might contribute to improving human health and well-being (for a more detailed discussion of inulin-type fructans and lipid metabolism in man, see Delzenne and Beylot this supplement).

\section{Inulin-type fructans and the body's defence functions}

The defence functions of the body are multiple, involving different organs, different mechanisms and targeting different potential aggressors. The body is thus well protected and in a healthy individual these multiple defence functions should exert an efficient protection. However genetic predispositions, ageing, stress, as well as lack of sufficient physical activity and an unbalanced diet are all factors that are likely to weaken these functions and consequently create conditions for increased sensitivity to external aggressions, both chemical and biological. It is one of the main objectives of functional food science to identify food components that have the capacity to positively modulate defence functions so as to help individuals to strengthen, restore or rebalance. Data already support the hypothesis that inulin-type fructans classify among the potential functional food ingredients capable of playing such roles. Indeed, they beneficially affect a series of gastrointestinal functions by modulating both the structure/composition as well as miscellaneous activities of the mucosa and the microflora. They also affect intestinal epithelium by improving mucosal morphology, thickening and improving the composition of the mucins. As a consequence they improve colonization resistance and prevent bacterial translocation (at least when tested in an appropriate model), and finally they contribute to improving both chemical and enzymatic safeguard functions in the gastrointestinal tract.

Inulin-type fructans also beneficially affect the immune system especially the intestinal immune functions by targeting gutassociated lymphoid tissues and especially Peyer's patches, and consequently they have been shown to reduce the risk of diseases related to dysfunction of gastrointestinal defence functions, an indirect but strong evidence for a beneficial effect (for more details see Guarner and Watzl et al. this supplement).

Regarding the risk of colon cancer, inulin-type fructans have the capacity to suppress chemically induced colon carcinogenesis both in mice and rats, and such an effect is likely to be potentiated in synbiotic preparations with lactic acid bacteria (for a detailed discussion see Pool-Zobel, this supplement). It has been hypothesized that inulin HP and Synergy ${ }^{\circledR} 1$ are more active than oligofructose because the long-chain molecules are likely to be more slowly fermented in the large bowel, thus prolonging their effects in the transverse and distal colon (Reddy et al. 1997; Poulsen et al. 2002). Indeed, the shortest oligomers of oligofructose are rapidly and quantitatively fermented already in the proximal colon and thus never arrive in the distal colon. Inulin HP and Synergy ${ }^{\circledR} 1$ act mostly during the promotion phase of the carcinogenic process and their effect is on the incidence, the yield, as well on the multiplicity of aberrant crypt foci, tumours and even cancers. Not only do they reduce the number and the size of lesions but also they reduce the risk of progression of these lesions towards malignancy. They thus classify as negative modulators of the carcinogenic process. The mechanisms proposed to explain these beneficial effects include changes in the composition and/or activity of colonic microflora (the prebiotic effect), and in the composition of the SCFA pool and especially an increased relative proportion of butyrate as a result of their anaerobic fermentation. These effects fit well with the concept of changes in metabolic and proliferative homeostasis in the large bowel and especially the colonic mucosa. In addition, inulin-type fructans strengthen and stimulate gastrointestinal defence functions and especially the intestinal immunity, two effects that certainly improve resistance to cancer development (for more details see Pool-Zobel and Van Loo et al. this supplement). Besides their effect (both direct and indirect) on the risk of diseases related to dysfunction of gastrointestinal defence functions, inulintype fructans have also been shown to possibly contribute to reducing the risk of diseases related to dysfunction of systemic defence functions. Essentially, this has been shown using experimental models of systemic infection, chemically induced mammary carcinogenesis, growth and metastasis of implanted tumour and cancer therapy.

Besides their effect (both direct and indirect) on the risk of diseases related to dysfunction of gastrointestinal defence functions, inulin-type fructans have also been shown to possibly contribute to reducing the risk of diseases related to dysfunction of systemic defence functions. Essentially in experimental models, it has been shown that supplementing diet with inulin-type fructans:

- reduces systemic infection (Buddington et al. 2002);

- negatively modulates chemically induced mammary carcinogenesis (Taper \& Roberfroid, 1999);

- retards the growth of implanted tumour (Taper et al. 1997, 1998);

- reduces the incidence of metastasis in a model involving the intramuscular transplantation of viable TLT cells into young male C3H mice (Taper \& Roberfroid, 2000);

- potentiates the effectiveness of cancer therapy (Taper \& Roberfroid, 2002a,b).

The data available today are almost exclusively experimental and there is an urgent need to design human intervention studies to test the hypotheses that are already supported by sound experimental data. The problem with the defence functions is that we still miss in many cases relevant and validated direct biomarkers of these functions that furthermore do not require invasive methods of clinical investigation. Indirect assessment of the state of well-being and health is thus probably, today, the method of choice.

An example of such an approach is the SYNCAN project in which inulin-type fructans and especially Synergy ${ }^{\circledR} 1$ has been tested in a multi-centre human intervention nutrition trial that 
was funded by the European Union (EU project QLK1-199900346 DG XII Research, EU; for more details see Van Loo et al. this supplement). Other examples are the double-blind, randomized controlled studies specifically designed to assess several clinical parameters related to common acute paediatric illnesses or the immunological response to measles vaccine in infants and toddlers, supplemented with oligofructose (Saavedra et al. 1999; Saavedra \& Tschernia, 2002; for more details see Veereman in this supplement).

\section{Conclusions and perspectives}

What makes a food 'functional' is the scientific demonstration that it beneficially affects functions in the body beyond what could be expected from basic nutrition. Concerning inulin-type fructans and by reference to the strategy for functional food development, this conclusion thus concentrates on

- basic scientific knowledge and experimental data to identify potential functional effects as well as to formulate hypotheses to be tested in human nutrition intervention studies;

- results of human nutrition intervention trials to substantiate claims (mainly type A but also a few type B).

As summarized in the different paragraphs, the effects of inulin-type fructans have been investigated in different domains of interest using a wide variety of experimental models and human trials. These domains classify in one of the following categories:

- Category 1: Experimental results exist that have been evaluated and used to justify human intervention studies; confirmatory human data of these human trials are available to substantiate claims. The domains included in this category are dietary fibre and bowel functions, gut microflora, gastrointestinal absorption of minerals and lipid (triacylglycerols) metabolism (Table 1).

- Category 2: Data from different experimental models are convincing, preliminary human data are available, and sound hypotheses exist, but more human nutrition trials are necessary to substantiate claims. The domains included in this category are cholesterol metabolism, gut-associated immune functions, inflammatory bowel diseases and colon cancer (Table 2).

- Category 3: Recent experimental investigations have generated promising results that justify more extensive studies including, in some cases, preliminary tests in human volunteers. The domains that are included in this category are bone health, gastrointestinal endocrinology, cancer therapy, behaviour and cognitive performance, etc. (Table 3).

The claims that are or might become scientifically substantiated are:

- inulin-type fructans are fermentable dietary fibres and help improve gut functions especially by improving regularity, by increasing stool frequency, and by faecal bulking;

- inulin-type fructans are bifidogenic and prebiotic;

- inulin-type fructans increase $\mathrm{Ca}$ absorption;

- inulin reduces triglyceridaemia in hyperlipidaemic individuals.

Inulin-type fructans thus classify as functional food ingredients that target gastrointestinal functions but also, most likely via their effects on the gut and the gut microflora, systemic functions that are known to be closely related to health and well-being.

It is thus not surprising that these ingredients are attracting interests as potential 'feel good' factors.

Recently, the WHO defined health as 'a state of complete physical, mental and social well-being and not merely the absence of disease or infirmity'. Thus to study the impact of nutrition on health cannot anymore be done without due consideration of the concept of well-being. In the occidental-industrialized world the life expectancy is now over 72 years and it is expected that, within the next 20 years, more than $50 \%$ of the population will be $65+$. As such, the well-being aspect of human health is getting more and more relevance. But the ageing population is by no means the only target group. Often facing stress as well as increasingly demanding working conditions, younger populations are also concerned when targeting a better well-being, especially in a society confronted with strong economic competition. Moreover even in infants, nutrition is a key element of well-being through harmonization of physiological developments to guarantee improved quality of life, e.g. the key role of early life nutrition in the balanced development of the immune system $\left(\mathrm{TH}_{1} / \mathrm{TH}_{2}\right.$ ratio).

In that context, gastrointestinal functions and especially colonic functions (e.g. control of the colonic environment, regulation of hormone-dependent metabolic processes, modulation of the brain-gut axis, systemic impact of gut fermentation products and activity of the immune system) deserve special attention. Indeed, disturbances of colon functions may lead to dysfunction not only in the gut but also in the whole body. The classical

Table 1. Experimental and human data that substantiate claims on inulin-type fructans: summary presentation

\begin{tabular}{|c|c|c|}
\hline Property or target functions & Supportive evidence & Claims \\
\hline Dietary fibre & $\begin{array}{l}\text { Oligo/polysaccharide, resistant to digestion, } \\
\text { fermentation }\end{array}$ & Inulin-type fructans are dietary fibre \\
\hline Bowel functions, stool production & $\begin{array}{l}\text { Bulking effect, regulation of stool production, } \\
\text { improved stool consistency }\end{array}$ & Inulin-type fructans regulate bowel functions \\
\hline Colonic microflora & $\begin{array}{l}\text { Substrates for anaerobic saccharolytic fermentation, } \\
\text { selective stimulation of growth of health-promoting } \\
\text { bacteria (e.g. bifidobacteria) }\end{array}$ & Inulin-type fructans are prebiotic \\
\hline $\begin{array}{l}\text { Gastrointestinal absorption of } \mathrm{Ca} \\
\text { and } \mathrm{Mg}\end{array}$ & $\begin{array}{l}\text { Increased absorption of } \mathrm{Ca}-\text { animal data, human data, } \\
\text { increased absorption of } \mathrm{Mg} \text { - animal data, human data }\end{array}$ & $\begin{array}{l}\text { Inulin-type fructans increase } \mathrm{Ca} \\
\text { absorption and } \mathrm{Mg} \text { absorption }\end{array}$ \\
\hline Lipid homeostasis & $\begin{array}{l}\text { Reduction of triglyceridaemia - animal data, human } \\
\text { data (slightly hypertriglyceridaemic), mechanistic data } \\
\text { (reduced hepatic lipogenesis) }\end{array}$ & $\begin{array}{l}\text { Inulin-type fructans reduce triglyceridaemia } \\
\text { in slightly hypertriglyceridaemic individuals }\end{array}$ \\
\hline
\end{tabular}


Table 2. Data on inulin-type fructans that support hypotheses to be tested in human nutrition and clinical intervention studies: summary presentation

\begin{tabular}{ll}
\hline Property or target functions & Supportive evidence \\
\hline Bone health & Improved bone: mineral content, mineral density, structure \\
Lipid homeostasis & Reduced cholesterolaemia \\
Immunostimulation & Improved resistance to common infections in children, improved response to vaccination \\
Colon cancer & Animal data in different experimental models + SYNCAN \\
Inflammatory bowel diseases & Attenuation of inflammatory responses, improved defences \\
\hline
\end{tabular}

Table 3. Data on inulin-type fructans that require more experimental research to support hypotheses to be tested in human nutrition and clinical intervention studies: summary presentation

\begin{tabular}{ll}
\hline Property or target functions & Supportive evidence \\
\hline Gastrointestinal absorption of minerals & Increased absorption of Fe, Cu, Zn \\
Lipid homeostasis & Reduction of lipid pool in obese rats \\
Defence mechanisms & Improved barrier functions, improved resistance to intestinal infections \\
Cancer development & Slowing down of tumour growth, reduction of risk of metastasis, improved efficacy of cancer therapies \\
Inflammatory bowel diseases & Reduction of risk and improved management of necrotizing enterocolitis in preterm infants \\
Gastrointestinal endocrinology & Stimulation of production of intestinal hormonal peptides (gastric inhibitory peptide, glucagon-like peptide-1, \\
& \\
\hline
\end{tabular}

view that the human colon is an organ (or a 'tube') that absorbs salt and water and provides a mechanism for the orderly disposal of waste products of digestion is no longer appropriate. Indeed the colon has a major role in digestion (as achieved by the microbial fermentation) through the salvage of energy. But it also contributes to the absorption of nutrients like minerals and vitamins; it plays a key role in protecting the body against translocation of bacteria and finally it is active as an endocrine (via the gastrointestinal peptides) as well as an immune organ (Cummings, 1997). It is also involved in miscellaneous diseases from acute infections and diarrhoea or constipation to chronic diseases like inflammatory bowel diseases, irritable bowel syndrome or cancer (Cummings, 1997). The reason why the colon plays such important physiological roles originates in its unique composition that associates pluricellular eukaryotic epithelial tissue and a population of unicellular (mostly prokaryotic) micro-organisms that collaborate in maintaining health and well-being. Indeed, the microflora that symbiotically colonizes the large bowel is a key player in maintaining the colon (and thus the whole body) healthy as well as in feeling well. But that population of unicellular micro-organisms is complex and highly diversified. To better understand the microflora and its symbiosis with the intestine, we hypothesize that, 'stimulated' by the complexity of its host's pluricellular tissue, the intestinal microflora has itself developed during evolution, and continues to develop during individual life, as a population of myriads of unicellular micro-organisms belonging to hundreds of genera, species and strains that not only live close together but actively collaborate to reach a (sometimes precarious) balanced activity that has become essential not only for health and well-being but simply for life. It can even further be speculated that it is in fact two 'pluricellular' worlds (one eukaryotic and one mostly prokaryotic) that live together and cooperate in the large bowel. Such a hypothesis would suggest that, like the different eukaryotic cells of a tissue (especially the immune system that is composed of mostly isolated specialized cells that interact and cooperate to neutralize and eliminate antigens), the various genera, species and strains of micro-organisms that colonize the digestive tract are specialized cells that form a complex tissue-like structure in which the different types of 'specialized' (but we still have to identify most of these specializations) cells interact to perform a series of physiological functions. Intestinal health and well-being would then result from interactions within and between these two pluricellular worlds, the interaction between the two worlds being referred to as 'crosstalk' (Khöler et al. 2003). The multicellular prokaryotic tissue-like entity would benefit from but would also provide benefits to the intestinal mucosa (i.e. the whole and complex pluricellular tissue) and vice versa. A major determinant of these interactions would be the composition of these two worlds, especially that of the prokaryotic population that establishes very early in life immediately after birth but can also be modulated later in life by the diet, and may change during life, becoming more and more complex but also perhaps more fragile as body ages. Through modulation of the composition of the colonic microbiota it thus becomes possible to influence large bowel functions but also to act, indirectly, on systemic functions and finally the host's health and well-being. Inversely it cannot be excluded that systemic dysfunction elsewhere in the body's organs influences the composition of the colonic flora and, as a consequence, the activities and the colonic functions.

By their specific effects, inulin-type fructans have the capacity to improve the composition, the activity and the functionality of both the colonic microflora and the intestinal mucosa, and to optimize the interactions between these two 'pluricellular' tissue and tissue-like structures thus creating the conditions for better intestinal health and well-being.

They do so because they beneficially affect three essential processes in the colon:

- Feeding because of resistance to digestion and no effect on digestion of nutrients, fermentation in the large bowel and improved bowel functions.

- Functioning due to activity of the microflora (i.e. more saccharolytic and less proteolytic fermentation or less putrefaction) producing a healthier pool of SCFA (i.e. more 
butyrate) and a more acidic environment; to composition and activity of the mucosa (i.e. in term of cell proliferation, cell differentiation, mucin composition, immune functions; mineral absorption and endocrine activities).

- Protecting through barrier effect against pathogens, prevention of inflammation and suppression of carcinogenesis.

But and because they improve intestinal health and well-being, inulin-type fructans are also likely to improve systemic health and well-being as shown by their effects on lipid metabolism most probably by modulating the expression of genes of hepatic lipogenic enzymes, on circulating levels of incretins and other gastrointestinal peptides (e.g. gastric inhibitory peptide, glucagon-like peptide-1, peptide YY and ghrelin), on systemic infections, on systemic immunities, and on tumour growth and tumour metastasis.

For all the reasons just discussed and because of accumulating scientific evidence, supplementation of miscellaneous food products with inulin-type fructans is becoming a target for the food industry and many different products (about 2500) are already sold worldwide but still a minority uses claims or advocates nutritional benefits.

In terms of perspectives, the future of research is in designing human nutrition intervention trials.

\section{References}

Apajalahti JHA, Kettunen H, Kettunen A, Holben WE, Nurminen PH, Rautanen N \& Mutanen M (2002) Culture-independent microbial community analysis reveals that inulin in the diet primarily affects previously unknown bacteria in the mouse cecum. Appl Environ Microbiol 68, 4986-4995.

Berg RD (1996) The indigenous gastrointestinal microflora. Trends Microbiol 4, 430-435.

Bielecka M, Biedrzycka E \& Majkowska A (2002a) Selection of probiotics and prebiotics and confirmation of their in vivo effectiveness. Food Res Int 35, 125-131.

Bielecka M, Biedrzycka E, Majkowska A, Juskiewicz J \& Wroblewska M (2002b) Effect of non-digestible oligosaccharides on gut microecosystem in rats. Food Res Int 35, 139-144.

Blaut M, Collins MD, Welling GW, Doré J, Van Loo J \& de Vos W (2002) Molecular biological methods for studying the gut microbiota: the EU human gut flora project. Br J Nutr 87, S203-S211.

Bouhnik Y, Flourié B, Riottot M, Bisetti N, Gailing MF, Guibert A, Bornet F \& Rambaud JC (1996) Effects of fructooligosaccharides ingestion on fecal bifidobacteria and selected metabolic indexes of colon carcinogenesis in healthy humans. Nutr Cancer 26, 21-29.

Bouhnik Y, Vahedi K, Achour L, et al. (1999) Short-chain fructo-oligosaccharide administration dose dependently increases fecal bifidobacteria in healthy humans. J Nutr 129, 113-116.

Brichard S (1997) Influence de mesures nutritionnelles sur l'homéostasie glucidique du rat diabétique. PhD Thesis, Université Catholique de Louvain.

Buddington KK, Donahoo JB \& Buddington RK (2002) Dietary oligofructose and inulin protect mice from enteric and systemic pathogens and tumor inducers. $J$ Nutr 132, 472-477.

Buddington RK, Williams CH, Chen SC \& Witherly SA (1996) Dietary supplement of Neosugar alters the faecal flora and decreases the activities of some reductive enzymes in human subjects. Am J Clin Nutr 63, 709-716.

Cashman K (2002) Calcium intake, calcium bioavailability and bone health. Br J Nutr 87, Suppl. 2, S169-S177.

Coudray C, Bellanger J, Castíglia-Delavaud C, Vermorel V \& Rayssiguier Y (1997) Effect of soluble or partly soluble dietary fibres supplementation on absorption and balance of calcium, magnesium, iron and zinc in healthy young men. Eur J Clin Nutr 51, 375-380.
Coudray C, Tressol JC, Gueux E \& Rayssiguier Y (2003) Effects of inulin-type fructans of different chain length and type of branching on intestinal absorption of calcium and magnesium in rats. Eur $J$ Nutr 42, 91-98.

Coussement P (1999) Inulin and oligofructose: safe intakes and legal status. J Nutr 129, 1412S-1417S.

Cummings JH (1997) The Large Intestine in Nutrition and Disease. Danone Chair Monograph. Brussels: Institut Danone.

Cummings JH \& Macfarlane GT (1997) Colonic microflora: nutrition and health. Nutrition 13, 476-478.

Daubioul C, De Wispelaere L, Taper H \& Delzenne N (2000) Dietary oligofructose lessens hepatic steatosis, but does not prevent hypertriglyceridemia in obese Zucker rats. J Nutr 130, 1314-1319.

De Leenheer L (1996) Production and use of inulin: industrial reality with a promising future. In Carbohydrates as Organic Raw Materials III, pp. 67-92 [H Van Bekkum, H Röper and F Voragen, editors]. New York: VCH Publishing Inc.

Delzenne N \& Roberfroid MB (1994) Physiological effects of nondigestible oligosaccharides. Lebensm-Wiss Technol 27, 1-6.

Delzenne N, Kok N, Deloyer P \& Dandrifosse G (2000) Polyamines as mediators of physiological effects of dietary oligofructose in rats. $J$ Nutr 130, 2456-2460.

Delzenne NM, Daubioul C, Neyrinck M, Lasa M \& Taper HS (2002) Inulin and oligofructose modulate lipid metabolism in animals: review of biochemical events and future prospects. Br J Nutr 87, Suppl. 2, S255-S259.

Demigné C, Remesy C \& Morand C (1999) Short chain fatty acids. In Colonic Microbiota, Nutrition and Health, pp. 55-70 [G Gibson and M Roberfroid, editors]. Dordrecht: Kluwer Academic.

Diplock AT, Aggett PJ, Ashwell M, Bornet F, Fern EB \& Roberfroid MB (1999) Scientific concepts of functional foods in Europe: consensus document. Br J Nutr 81, Suppl. 1, S1-S28.

Fairweather-Tait SJ \& Johnson IT (1999) Bioavailability of minerals. In Colonic Microbiota: Nutrition and Health, pp. 233-244 [GR Gibson and MB Roberfroid, editors]. Dordrecht: Kluwer Academic.

Farnworth ER (1993) Fructans in human and animal diets. In Science and Technology of Fructans, pp. 258-270 [M Suzuki and NJ Chatterton, editors]. Boca Raton, FL: CRC Press.

Fooks LJ \& Gibson GR (2002) In vitro investigations of the effect of probiotics and prebiotics on selected human intestinal pathogens. FEMS Microbiol Ecol 39, 67-75.

Gibson GR (1998) Dietary modulation of human gut microflora using prebiotics. Br J Nutr 80, S209-S212.

Gibson GR \& Roberfroid MB (1995) Dietary modulation of the human colonic microbiota: introducing the concept of prebiotics. J Nutr $\mathbf{1 2 5}$, $1401-1412$.

Gibson G \& Roberfroid M (editors) (1999) Colonic Microbiota, Nutrition and Health. Dordrecht: Kluwer Academic.

Gibson GR, Beatty ER, Wang X \& Cummings JH (1995) Selective stimulation of bifidobacteria in the human colon by oligofructose and inulin. Gastroenterology 108, 975-982.

Gibson GR, Probert HM, Rastall R, Van Loo JAE \& Roberfroid MB (2004) Dietary modulation of the human colonic microbiota: updating the concept of prebiotics. Nutr Res Rev, 17, 257-259.

Griffin IJ, Hicks PMD, Heaney RP \& Abrams SA (2003) Enriched chicory inulin increases calcium absorption in girls with lower calcium absorption. Nutr Res 23, 901-909.

Guigoz Y, Rochat F, Perruisseau-Carrier G, Rochat I \& Schiffrin EJ (2002) Effects of oligosaccharide on the faecal flora and non-specific immune system in elderly people. Nutr Res 22, 13-25.

Hanson LA \& Yolken RH (editors) (1999) Probiotics and other Nutritional Factors, and Intestinal Microflora. Philadelphia, PA: Lippincott-Raven.

Harmsen HJM, Raangs GC, Franks AH, Wildeboer-Veloo CM \& Welling GW (2002) The effect of the prebiotic inulin and the probiotic Bifidobacterium longum on the fecal microflora of healthy volunteers measured by FISH and DGGE. Microb Ecol Health Dis 14, 211-219. 
Hidaka H, Eida T, Takizawa T, Tokunahga T \& Tashiro Y (1986) Effects of fructo-oligosaccharides on intestinal flora and human health. Bifidobacteria Microflora 5, 37-50.

Hidaka H, Tashiro Y \& Eida T (1991) Proliferation of bifidobacteria by oligosaccharides and their useful effect on human health. Bifidobacteria Microflora 10, 65-79.

Holloway L, Moyniham S \& Friedlander AL (2005) Effects of Raftilose synergy 1 on mineral absorption and markers of bone turnover in postmenopausal women.

Kennefick S \& Cashman KD (2000) Investigation of an in vitro model for predicting the effect of food components on calcium availability from meals. Int J Food Sci Nutr 51, 45-54.

Khöler H, McCormick BA \& Walker WA (2003) Bacterial-enterocyte crosstalk: cellular mechanisms in health and disease. J Pediatr Gastroenterol 36, 175-185.

Kleessen B, Sykura B, Zunft HJ \& Blaut M (1997) Effects of inulin and lactose on faecal microflora, microbial activity and bowel habit in elderly constipated persons. Am J Clin Nutr 65, 1397-1402.

Kleessen B, Hartmann L \& Blaut M (2001) Oligofructose and long-chain inulin influence the gut microbial ecology of rats associated with a human faecal flora. Br J Nutr 86, 291-300.

Kleessen B, Hartmann L \& Blaut M (2003) Fructans in the diet cause alterations of intestinal mucosa architecture, released mucins and mucosa-associated bifidobacteria in gnotobiotic, rats. Br J Nutr 89, $597-606$

Kok N, Morgan L, Williams C, Roberfroid M, Thissen JP \& Delzenne N (1998) Insulin, glucagon-like peptide 1, glucose-dependent insulinotropic polypeptide and insulin-like growth factor I as putative mediators of the hypolipidemic effect of oligofructose in rats. $J$ Nutr 128, 1099-1103.

Kruse HP, Kleessen B \& Blaut M (1999) Effects of inulin on faecal bifidobacteria in human subjects. Br J Nutr 82, 375-382.

Langlands SJ, Hopkins MJ, Coleman N \& Cummings JH (2004) Prebiotic carbohydrates modify the mucosa associated microflora of the human large bowel. Gut 53, 1610-1616.

Letexier D, Diraison F \& Beylot M (2003) Addition of inulin to a moderately high-carbohydrates diet reduces hepatic lipogenesis and plasma triacylglycerol concentrations in humans. Am J Clin Nutr 77, 559-564.

Macfarlane S, Cummings JH \& Macfarlane GT (1999) Bacterial colonization of surfaces in the large intestine. In Colonic Microbiota, Nutrition and Health, pp. 71-88 [GR Gibson and MB Roberfroid, editors]. Dordrecht: Kluwer Academic.

Mellander O (1950) The physiologic importance of the casein phosphopeptide calcium salt, II: per oral calcium dosage of infants. Acta Soc Med (Uppsala) 55, 247-255.

Menne E, Guggenbuhl N \& Roberfroid M (2000) Fn-type chicory inulin hydrolysate has a prebiotic effect in humans. J Nutr 130, 1197-1199.

Menzies IS (1974) Absorption of intact oligosaccharides in health and disease. Biochem Soc Trans 2, 1042-1047.

Mitsuoka T, Hidaka H \& Eida T (1987) Effect of fructo-oligosaccharides on intestinal microflora. Die Nahrung 31, 427-436.

Moshfegh AJ, Friday JE, Goldman JP \& Chug Ahuga JK (1999) Presence of inulin and oligofructose in the diets of Americans. J Nutr 129, Suppl. 7S, 1407S-1411S.

Ohta A, Sakai K, Takasaki M \& Tokunaga T (1999) Evaluation of the action of calcium resorption enhancement of fructooligosaccharides in tablet candies for humans. Health Nutr Food Res 2, 37-43.

Oku T, Tokunaga T \& Hosoya N (1984) Nondigestibility of a new sweetener 'Neosugar' in the rat. J Nutr 114, 1574-1581.

Perrin IV, Marchesini M, Rochat FC, Schiffrin EJ \& Schilter B (2003) Oligofructose does not affect the development of type 1 diabetes mellitus induced by dietary proteins in the diabetes-prone BB rat model. Diabetes Nutr Metab 16, 94-101.

Perrin S, Warchol M, Grill JP \& Schneider F (2001) Fermentation of fructooligosaccharides and their components by Bifidobacterium infantis ATCC 15967 on batch culture in semi-synthetic medium. J Appl Microbiol 90, 859-865.
Poulsen M, Molck AM \& Jacobsen BL (2002) Different effects of short- and long-chained fructans on large intestinal physiology and carcinogen-induced aberrant crypt foci in rats. Nutr Cancer 42, 194-205.

Poxton IR, Brown R, Sawyer A \& Fergusson A (1997) Mucosa-associated bacterial flora of the human colon. J Med Microbiol 46, 85-91.

Quemener B, Thibault JF \& Coussement P (1994) Determination of inulin and oligofructose in food products and integration in the AOAC method for the measurement of total dietary fibre. Lebensm-Wiss Technol 27, $125-132$.

Rao V (2001) The prebiotic properties of oligofructose at low intake levels. Nutr Res 21, 843-848.

Reddy BS, Hamid R \& Rao CV (1997) Effect of dietary oligofructose and inulin on colonic preneoplastic aberrant crypt foci inhibition. Carcinogenesis 18, 1371-1374.

Roberfroid M (1993) Dietary fiber, inulin, and oligofructose: a review comparing their physiological effects. CRC Crit Rev Food Sci Nutr 33, $103-148$.

Roberfroid MB (1998) Prebiotics and synbiotics: concepts and nutritional properties. Br J Nutr 80, S197-S202.

Roberfroid M (2002) Functional foods: concepts and application to inulin and oligofructose. Br J Nutr 87, Suppl. 2, S139-S143.

Roberfroid M (2004) Inulin-type Fructans as Functional Food Ingredients. Boca Raton, FL: CRC Press.

Roberfroid MB (2004) Prebiotics: the concept revised. J Nutr.

Roberfroid MB \& Delzenne N (1998) Dietary fructans. Annu Rev Nutr 18, $117-143$.

Roberfroid MB \& Slavin J (2000) Nondigestible oligosaccharides. Crit Rev Food Sci Nutr 40, 461-480.

Roberfroid MB, Van Loo JAE \& Gibson GR (1998) The bifidogenic nature of chicory inulin and its hydrolysis product. J Nutr 128, 11-19.

Roberfroid M, Champ M \& Gibson G (2002) Nutritional and health benefits of inulin and oligofructose. Br J Nutr 87, Suppl. 2, S139-S311.

Rowland IR (1988) Interactions of the gut microflora and the host in toxicology. Toxicol Pathol 16, 147-153.

Rycroft CE, Jones MR, Gibson GR \& Rastall RA (2001) A comparative in vitro evaluation of the fermentation properties of prebiotic oligosaccharides. J Appl Microbiol 91, 878-887.

Saavedra JM \& Tschernia A (2002) Human studies with probiotics and prebiotics: clinical implications. Br J Nutr 87, Suppl. 2, S241-S246.

Saavedra JM, Tschernia A, Moore N, Abi-Hanna A, Coletta F \& Emenheiser C (1999) Gastrointestinal function in infants consuming a weaning food supplemented with oligofructose. J Paediatr Gastroenterol Nutr 29, A95.

Salminen S, Bouley C, Boutron-Ruault MC, et al. (1998) Functional food science and gastrointestinal physiology and function. Br J Nutr 80, Suppl. 1, S147-S171.

Sano T (1986) Effects of Neosugar on constipation, intestinal microflora, and gall bladder contraction in diabetics. In Proceedings of the Third Neosugar Research Conference, pp. 109-117. Tokyo: Meiji-Seika Publications.

Stürup S, Hansen M \& Molgaard C (1997) Measurement of ${ }^{44} \mathrm{Ca},{ }^{43} \mathrm{Ca}$ and ${ }^{42} \mathrm{Ca}{ }^{43} \mathrm{Ca}$ isotopic ratios in urine using high resolution inductively coupled plasma mass spectrometry. J Anal At Spectrom 12, 919-923.

Tahiri M, Tressol JC, Arnaud J, et al. (2003) Effect of short-chain fructooligosaccharides on intestinal calcium absorption and calcium status in postmenopausal women: a stable-isotope study. Am J Clin Nutr 77, 449-457.

Takahashi Y (1986) Effects of fructo-oligosaccharides in the chronicfailure patient. In Proceedings of the Third Neosugar Research Conference, pp. 21-30. Tokyo: Meiji-Seika Publications.

Taper HS \& Roberfroid MB (1999) Influence of inulin and oligofructose on breast cancer and tumour growth. J Nutr 129, 1488S-1491S.

Taper HS \& Roberfroid MB (2000) Inhibitory effect of dietary inulin or oligofructose on the development of cancer metastases. Anticancer Res 20, 4291-4294.

Taper HS \& Roberfroid MB (2002a) Non-toxic potentiation of cancer 
radiotherapy by dietary oligofructose and inulin. Anticancer Res $\mathbf{2 2}$, 3319-3324.

Taper HS \& Roberfroid MB (2002b) Inulin/oligofructose, and anticancer therapy. Br J Nutr 87, Suppl. 2, S283-S286.

Taper HS, Delzenne NM \& Roberfroid MB (1997) Growth inhibition of transplantable mouse tumors by non-digestible carbohydrates. Int $J$ Cancer 71, 1109-1112.

Taper HS, Lemort C \& Roberfroid MB (1998) Inhibition effect of dietary inulin and oligofructose on the growth of transplantable mouse tumor. Anticancer Res 18, 4123-4126.

Teuri U, Kärkkäinen M, Lamberg-Allardt C \& Korpela R (1999) Addition of inulin to breakfast does not acutely affect serum ionised calcium and parathyroid hormone concentrations. Ann Nutr Metab 43, 356-364.

Tuohy KM, Finlay RK, Wynne AG \& Gibson GR (2001a) A human volunteer study on the prebiotic effects of HP-inulin - faecal bacteria enumerated using fluorescent in situ hybridization (FISH). Ecol Environ Microbiol 7, 113-118.

Tuohy KM, Kolida S, Lustenberger A \& Gibson GR (2001b) The prebiotic effects of biscuits containing partially hydrolysed guar gum and fructooligosaccharides - a human volunteer study. Br J Nutr 86, 341-348.

Uenishi K, Ohta A, Fukushima Y \& Kagawa Y (2002) Effect of a malt drink containing fructooligosaccharides on calcium absorption and safety of long term administration. Jpn J Nutr Diet 60, 11-18.

Van den Heuvel EG, Schaafsma G, Muijs T \& van Dokkum W (1998) Nondigestible oligosaccharides do not interfere with calcium and nonhemeiron absorption in young, healthy men. Am J Clin Nutr 67, 445-451.
Van Loo J \& Jonkers N (2001) Evaluation in human volunteers of the potential anticarcinogenic activities of novel nutritional concepts: prebiotics, probiotics and synbiotics (the SYNCAN project QLK11999-00346). Nutr Metab Cardiovasc Dis 11, Suppl., 87-93.

Van Loo J, Coussement P, De Leenheer L, Hoebregs H \& Smits G (1995) On the presence of inulin and oligofructose as natural ingredients in the Western diet. Crit Rev Food Sci Nutr 35, 525-552.

Waterhouse AL \& Chatterton NJ (1993) Glossary of fructan terms. In Science and Technology of Fructans, pp. 2-7 [M Suzuki and NJ Chatterton, editors]. Boca Raton, FL: CRC Press.

Weaver CM \& Liebman M (2002) Biomarkers of bone health appropriate for evaluating functional foods designed to reduce risk of osteoporosis. Br J Nutr 88, Suppl. 2, S225-S232.

Whiting SJ \& Wood RJ (1997) Adverse effects of high calcium diets in humans. Nutr Rev 55, 1-9.

Williams CH, Witherly SA \& Buddington RK (1994) Influence of dietary Neosugar on selected bacteria groups of the human fecal microbiota. Microb Ecol Health Dis 7, 91-97.

Wolf BW, Firkins JL \& Zhang X (1998) Varying dietary concentrations of fructooligosaccharides affect apparent absorption and balance of minerals in growing rats. Nutr Res 18, 1791-1806.

Yamada S (1994) ${ }^{45} \mathrm{Ca}$ kinetics and balance study. A useful method for analysing the effects of drugs on calcium metabolism. In Pharmacological Approach to Study the Formation and the Resorption Mechanism of Hard Tissues, pp. 75-92 [H Ogura, editor]. Tokyo: EuroAmerica Publishers. 